\title{
Hybrid Electron Beam Powder Bed Fusion Additive Manufacturing of Ti-6Al-4V: Processing, Microstructure, and Mechanical Properties
}

\author{
R. TOSI, E. MUZANGAZA, X.P. TAN, D. WIMPENNY, and M.M. ATTALLAH
}

\begin{abstract}
Processing, microstructure, and mechanical properties of the hybrid electron beam powder bed fusion (E-PBF) additive manufacturing of Ti-6Al-4V have been investigated. We explore the possibility of integrating the substrate as a part of the final component as a repair, integrated, or consolidated part. Various starting plate surface conditions are used to understand the joining behavior and their microstructural properties in the bonding region between the plate and initial deposited layers. It is found that mechanical failures mainly occur within the substrate region due to the dominant plastic strains localized in the weaker Ti-6Al-4V substrate. The hybrid concept is successfully proven with satisfactory bonding performance between the E-PBF build and substrate. This investigation improves the practice of using the hybrid E-PBF additive manufacturing technique and provides basic understanding to this approach.
\end{abstract}

https://doi.org/10.1007/s11661-021-06565-2

(C) The Author(s) 2022

\section{INTRODUCTION}

Currently, the increase in productivity is one of the main pursuing areas of investigation in additive manufacturing (AM). This is mainly focused on improving the flexibility and reducing the cost, where new manufacturing approaches and new materials are at the centre of the intensive investigations from the AM community. Nevertheless, defining a suitable method which provides flexibility in an enclosed process such as the electron beam powder bed fusion (E-PBF) is a challenge. Several methods, for instance, using cheap powders for manufacturing, customizing the build envelope, increasing the layer thickness, improving the melting strategies, varying the settings during the process were tested to understand the flexibility of the E-PBF system and its potential advantages.

R. TOSI is with the School of Metallurgy and Materials, University of Birmingham, Birmingham B15 2TT, UK and also with the National Centre for Additive Manufacturing, The Manufacturing Technology Centre, Ansty Park, Coventry CV7 9JU, UK. Contact e-mail: Riccardo.tosi@slm-solutions.com E. MUZANGAZA and D. WIMPENNY are with the National Centre for Additive Manufacturing, The Manufacturing Technology Centre. X.P. TAN is with the Department of Mechanical Engineering, National University of Singapore, 9 Engineering Drive 1, Singapore 117575 , Singapore. Contact e-mail: XPTan@nus.edu.sg. M.M. ATTALLAH is with the School of Metallurgy and Materials, University of Birmingham.

Manuscript submitted March 22, 2021; accepted November 27, 2021. Article published online January 13, 2022
AM practitioners have explored the possibilities using multiple materials and combining different processes, from a conventional milling machine with a directed energy deposition (DED) system, ${ }^{[1]}$ to combine multi-materials within powder bed fusion (PBF) and DED builds, ${ }^{[2-4]}$ using an AMed component or part as a starting plate, ${ }^{[5,6]}$ or joining an E-PBF manufactured part with another Ti-6Al-4V component through linear friction welding, ${ }^{[7]}$ and repairing existing parts. ${ }^{[8]}$ These processes can be considered as hybrid AM which broadly refers to a multi-step manufacturing technology based on a main AM process with supplementary conventional processes or materials.

A multi-material metallic structure, investigated by Terrazas et al. ${ }^{[9]}$ was attempted using AMed Ti-6Al-4V parts and pure copper. They achieved multi-material tensile bars, by manufacturing the first half of the Ti-6Al-4V tensile bars with a standard starting plate, then the second half of the tensile bars using a copper mask where the Ti-6Al-4V half tensile bar was integrated. Then a final copper build was performed on the top of the titanium components generating full horizontal and vertical multi-material tensile bars. A microstructural investigation showed strong bonding in the transition zone. This technique demonstrated the flexibility of building on top of existing parts using a conventional machine adapted to the final goal of the experiment, which opens several possibilities such as adding material to existing or worn parts or manufacturing multi-material components.

Using the above approach, a "stop and go process" was performed by Hossain et al. ${ }^{10]}$ Using several manufacturing steps, an imbedded sensor was 
manufactured through six steps and two builds to enclose an alumina sensor inside a $\mathrm{Ti}-6 \mathrm{Al}-4 \mathrm{~V}$ part manufactured by E-PBF. They managed to build on the top side of a previously manufactured AMed part in E-PBF, leveling it with the starting plate and building up the final sealing part which sealed the part to a monoblock component. This advanced approach shows the benefit of encapsulating an external component inside a part manufactured inside the E-PBF in two stages, where an external component sits inside the machine during a build.

Mandil et al. ${ }^{[11]}$ investigated ways to build on top of end-of-life parts using an E-PBF system. The authors used a Ti-6Al-4V starting plate for a build in order to check the interface between the AM part and the substrate. Using standard E-PBF settings, they noticed strong bonding between the interface and the possibility of building new interfaces into an existing solid flat part. The ability to manufacture features onto existing parts, and the use of different materials, can provide a new range of manufacturing opportunities for E-PBF. The starting plate can be used as an integrating part of the component, or a real part can be used as a starting plate. More studies should be performed in this area to offer promising advanced manufacturing solutions.

It is worth noting that there are still limited research works on hybrid AM processes, particularly for the hybrid E-PBF technology. Due to the increase in maturity of the E-PBF technology, interests in its applications in hybrid manufacturing are supposed to be rapidly rising. More options in terms of material and process development are being developed to provide more flexibility and solutions while manufacturing parts with an E-PBF system. Literature has been considered to gain insight into its demand in the market and the advantages of being in vacuum environment which will favor the fusion bonding between the materials and consequently the mechanical properties. This study investigates a hybrid AM method using the starting plate as an integrated part of the substrate, and aims to exploring an effective way of significantly improving productivity of E-PBFed $\mathrm{Ti}-6 \mathrm{Al}-4 \mathrm{~V}$.

\section{EXPERIMENTAL PROCEDURES}

\section{A. 2.1. Substrate Preparation}

Two experiments were performed using different Ti-6Al-4V (Grade 5) hot-rolled and annealed substrate plates of 10 and $40 \mathrm{~mm}$ thick, respectively. Both have a surface area dimension of $170 \times 170 \mathrm{~mm}^{2}$ which is the standard Arcam A2 substrate size; and the area of preheating and melting were set according to the Arcam A2 platform. The first 10-mm-thick substrate was used to better understand the characteristics of the first few layers while modifying some machine settings, the substrate plate condition, and the beam focus in order to analyze the bonding characteristics achieved. The 40 $\mathrm{mm}$ substrate was then used to manufacture tensile specimens with the optimized settings analyzed during the first build. Microstructural and mechanical property evaluations were performed to capture the main differences under varied substrate surface conditions: as manufactured, Kroll etched, shot peened, and laser re-melted.

Flatness of the substrate is considered an important variable during normal builds. Given the scope of the hybrid build of re-melting a starting plate surface region, it is reasonable to suggest that the flatness should be less than the thickness of the layers $(70 \mu \mathrm{m})$. If it is outside the mentioned tolerance, the powder will not be evenly spread on the starting plate surface due to consequent risk of issues during the melting of the first few layers or potential faults taking place during the raking stage.

Surface roughness does not have a big impact on spreading the powder on the starting plate surface. Given that different surface treatment was imposed, the start plates showed different surface roughness (Sa) results that are listed in Table I. The Sa measurements were captured using an Alicona IF series 3D surface roughness system, with a filter of $2.5 \mathrm{~mm}$. The flat region scanned was $2 \times 2 \mathrm{~mm}^{2}$ in the middle region of the cuboids, which allowed to capture an average $\mathrm{Sa}$ of the specimen surfaces. There are only slight differences that the thicker $40 \mathrm{~mm}$ plate has rougher initial surfaces compared to the $10-\mathrm{mm}$-thick plate which does not change, in both cases, after the Kroll's etching treatment. The peening treatment decreases the surface roughness due to superficial compressive deformation taking place during the ball's impact on the substrate creating a rougher surface. After performing the laser re-melting treatments, the surface conditions showed improved and similar roughness compared to the raw material.

\section{B. Process Parameters}

During the generation of the build file, the Arcam A2 starting plate settings were used. This allowed the system to calculate the energy density needed in a 170 $\times 170 \mathrm{~mm}^{2}$ plate compared to the standard $350 \times 200$ $\mathrm{mm}^{2}$ version conventionally used with the Arcam A2XX system. The selection of the envelope was achieved through the Magics software which automatically calculates the energy density and the consequent heat balance needed for the manufacture of the reduced build size.

After the modification of the substrate with four different superficial conditions, three different beam focus conditions during melting were considered to better understand the impact of them in terms of energy density and bonding interface characteristics. The standard beam focus condition of $9 \mathrm{~mA}$ has been used as a reference value. In order to vary the standard value, two sets of variables below and above the standard value were identified. On top of the standard value of $9 \mathrm{~mA}$, beam focus values of 0 and $19 \mathrm{~mA}$ were chosen to be performed on each substrate condition with the manufacturing of four cubes per variable.

Preheat 1, preheat 2, and contour themes were kept the same for all the cubes. Table II shows the standard hatch melting settings used for the manufacturing of the 
cubes. Parallel "snake $X-Y$ " hatching scans were adopted during the melting of the layers with a $90 \mathrm{deg}$ rotation between each layer.

A constant current of $60 \mathrm{kV}$ and a layer thickness of $70 \mu \mathrm{m}$ were used during the build. On top of the three different E-PBF beam focus conditions (0, 9, and 19 $\mathrm{mA}$, respectively), a constant $\mathrm{SF}$ of 36 and a fixed line offset value of $0.2 \mathrm{~mm}$ during melting were used.

\section{Design of Experiment (DOE)}

Two different builds were made to better understand the bonding characteristics between the substrate and the AMed parts and to evaluate the mechanical properties. Pre-alloyed Ti-6Al-4V powder of 45 to $106 \mu \mathrm{m}$ from TLS was used to manufacture the parts with an A2XX Arcam E-PBF system. The first build, also known as DOE 1, had a 10-mm-thick starting plate and was used to analyze the fusion bonding between different beam focus offsets and starting plate preparation methods. Four $10 \times 10 \times 8 \mathrm{~mm}^{3}$ cuboids were manufactured for each beam focus variation $(0,9$ and 19 $\mathrm{mA}$ ) and surface condition, and a total of 48 cuboids were fabricated. Figure 1 shows the Ti-6Al-4V starting plate with four different $\mathrm{A}-\mathrm{B}-\mathrm{C}-\mathrm{D}$ surface regions, where 12 cuboids on each condition were manufactured. Numbers 1, 2, and 3 represent the different beam focus offsets of 0,9 , and $19 \mathrm{~mA}$, respectively, used during the build.

After the first build of 48 cuboids, a second build with a starting plate of $40 \mathrm{~mm}$ thickness was designed with tensile specimens. Figures 2(a) and (b) show the location of horizontal and vertical tensile bars built in different locations of the substrate during DOE 2. The aim of the design was focused on leaving the interface region close to the center of the gauge length for the vertical tensile ones, and asymmetrical (along the specimen axial) for the horizontal specimens. Vertically oriented 3-mm-thick in-situ shells with enclosed powder were manufactured to encapsulate lose pre-sintered powder to be HIP treated afterwards (Figures 2(c) and (d)). The

Table I. Surface Roughness (Sa) Captured in Different Substrate Surface Conditions for Two Thicknesses of Starting Plates

\begin{tabular}{lcc}
\hline Substrate Surface Condition & $10 \mathrm{~mm}(\mu \mathrm{m})$ & $40 \mathrm{~mm}(\mu \mathrm{m})$ \\
\hline As Manufactured & 1.0 & 2.0 \\
Etched & 1.0 & 2.0 \\
Shot Peened & 1.9 & 2.3 \\
Laser Re-melted & 0.7 & 0.7 \\
\hline
\end{tabular}

thermal post process allows for consolidation of the loose powder and the consequent ability to generate the tensile specimens. A pre-selected melting theme, from DOE 1, was used to perform all the tensile bars during DOE 2, the reasons for which are explained in the following sections.

\section{Materials Characterization and Mechanical Testing}

All samples were ground down from \#400 SiC (grid paper) to \#2400, followed by $9 \mu \mathrm{m}$ supreme diamond suspension or \#4000 SiC sandpaper, followed by a final polishing using $0.05 \mu \mathrm{m}$ silica dioxide suspension. For microstructure observation, chemical etching was carried out by swabbing the specimen in a Kroll etchant reagent (4 $\mathrm{ml}$ Hydrofluoric Acid, $196 \mathrm{ml}$ deionized water) for 5 to 10 seconds then submerging in water before spraying with ethanol and drying. Microstructure examination was carried out using the ZeissImager.M2m optical microscope (OM). Two scanning electron microscopes (SEM) were used during the analysis of the specimens: a desktop Deben TM 3000 for preliminary studies (due to the low specification of the system) and a state-of-the-art JEOL 7000 system for high-magnification inspection and detailed images. The post processing was performed at Hauck Heat Treatment Ltd (TTI), where a constant pressure of $103 \mathrm{MPa}$, a temperature of $920{ }^{\circ} \mathrm{C}$, and a holding time of 120 minutes were used during the HIPping process.

Microhardness measurements were carried out using a Buehler MicroMet 6030 on the $X-Z / Y-Z$ plane of the samples. After shaping the tensile specimens out of the Ti-6Al-4V starting plate, they were sent to Westmoreland Ltd. for machining and final tensile testing. Each three of the four samples were tested for mechanical properties comparison. One sample of each condition was kept for metallurgical analysis without being tested. ASTM E8 standards were followed for the manufacture of the tensile specimens tested.

\section{RESULTS AND DISCUSSION}

\section{A. Influence of Substrate Surface Conditions}

The analysis of the DOE 1 starting plate revealed that by preheating the substrate at $720{ }^{\circ} \mathrm{C}$, substantial residual stress relief took place, which had an impact on the flatness of substrates under different surface conditions. No traces of deformation bands were observed below the shot peened surface. By raising the substrate above $720^{\circ} \mathrm{C}$ for more than 2 hours, all the compressive stresses were released. Thus, it is suggested

Table II. E-PBF Hatch Melting Settings Used During the Hybrid Builds

\begin{tabular}{lccccc}
\hline System & Preheating $T\left({ }^{\circ} \mathrm{C}\right)$ & Line Order & $\begin{array}{c}\text { Line Offset } \\
(\mathrm{mm})\end{array}$ & Constant Current $(\mathrm{kV})$ & Beam Current $(\mathrm{mA})$ \\
\hline Arcam A2XX & 720 & 15 & 0.2 & 60 & 30 \\
\hline
\end{tabular}




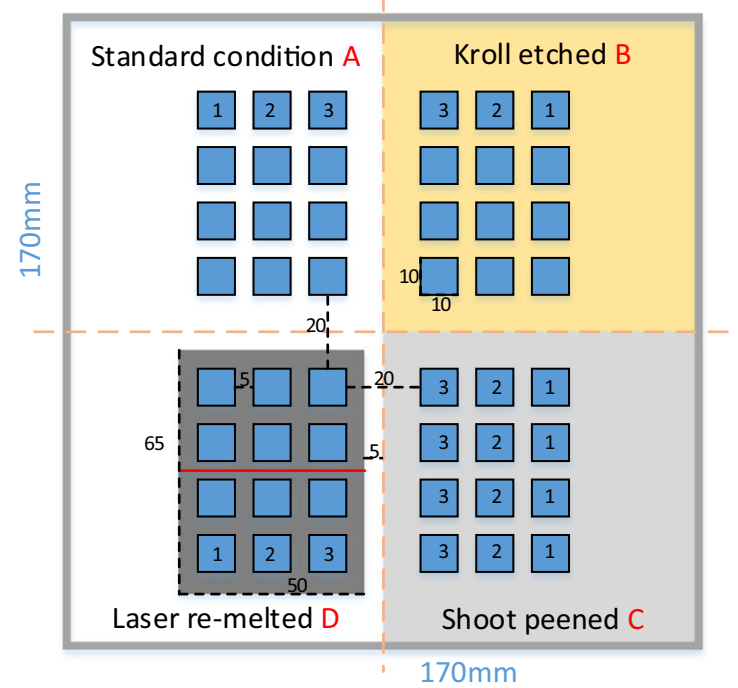

(a)

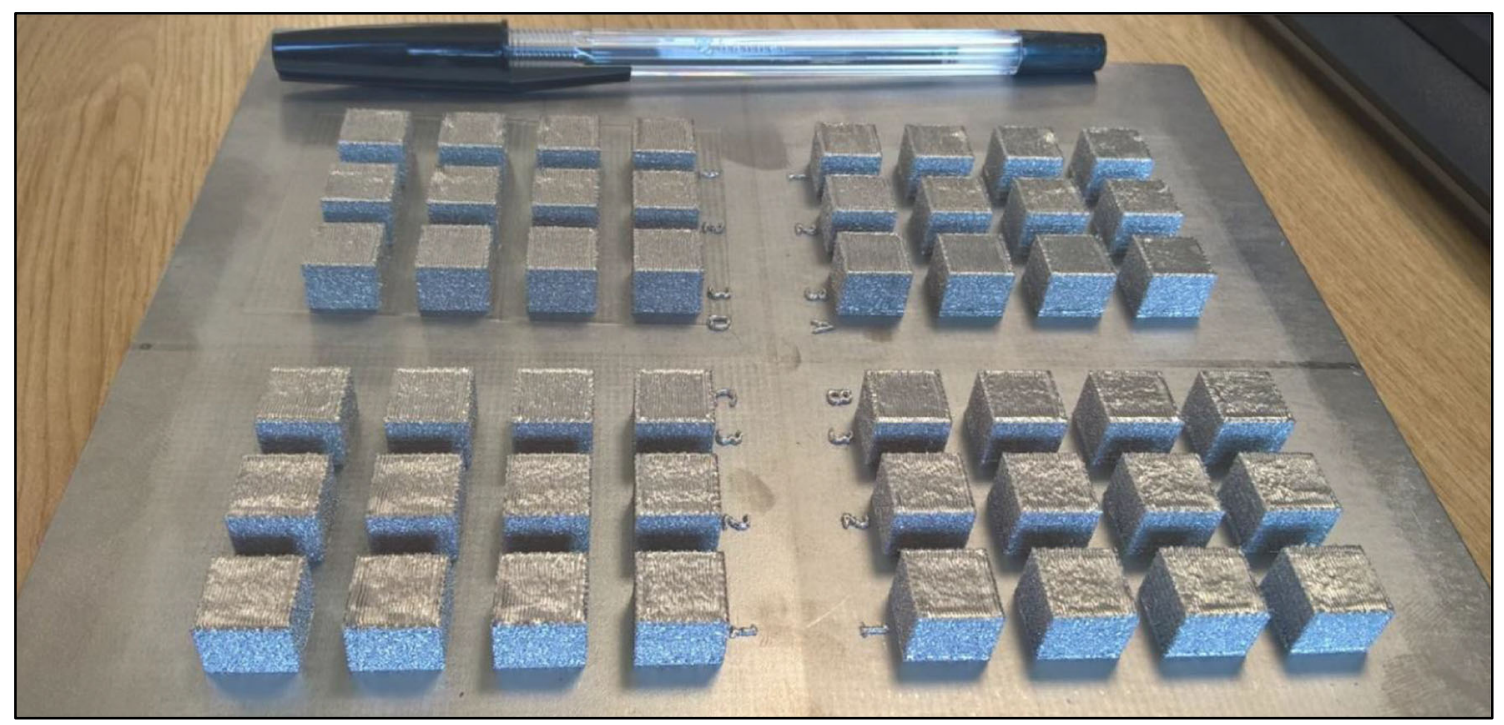

(b)

Fig. 1-(a) DOE 1 substrate design with cube designation numbers. (b) 48 cuboids manufactured on a 10-mm-thick Ti-6Al-4V substrate.

that the normal, etched, and shot peened surface conditions had the same metallurgical behavior before melting the first AMed layer. The laser re-melted region was $\sim 30$ to $40 \mu \mathrm{m}$ in depth, which was three times less than assumed. The reason for the low penetration achieved was mainly due to a poor laser offset calibration, which resulted in less energy density per area with a consequent reduction in the re-melted region.

After heating the 10 -mm-thick substrate to $720^{\circ} \mathrm{C}$, it was clear from the powder spread on it through the rake that the substrate was not completely flat, as it was sitting mainly in the central region of the starting plate. The convex shape observed was probably generated after the mechanical shot peening and the laser re-melting treatments, previously carried out on the substrate, generating residual compressive stresses on the top substrate and a consequent convex deformation of the plate. Despite that, the build started and ended without major issues. After the cooling down of the system, the substrate exhibited a final bending curve of $2 \mathrm{~mm}$ deep from the side to the middle of the substrate. The complete distortion may have occurred because of the low cooling rate of the material in the chamber, which relieved the residual compressive stresses generated during the mechanical surface treatment.

The second build, using a substrate $40 \mathrm{~mm}$ thick, did not show any superficial curves or bends. The rigidity of the thick substrate enables the starting plate avoid visible deformation or bending. However, having a thick substrate led to other issues such as the preheating $\mathrm{T}$ reading. In fact, the thermo-couple located at the bottom region of the starting plate was subject to a slow response from the heating up of the starting plate during the preheating phase. The delay time allowed, to transfer the heat from the top heated region to the low area of the starting plate, was very slow and difficult to 


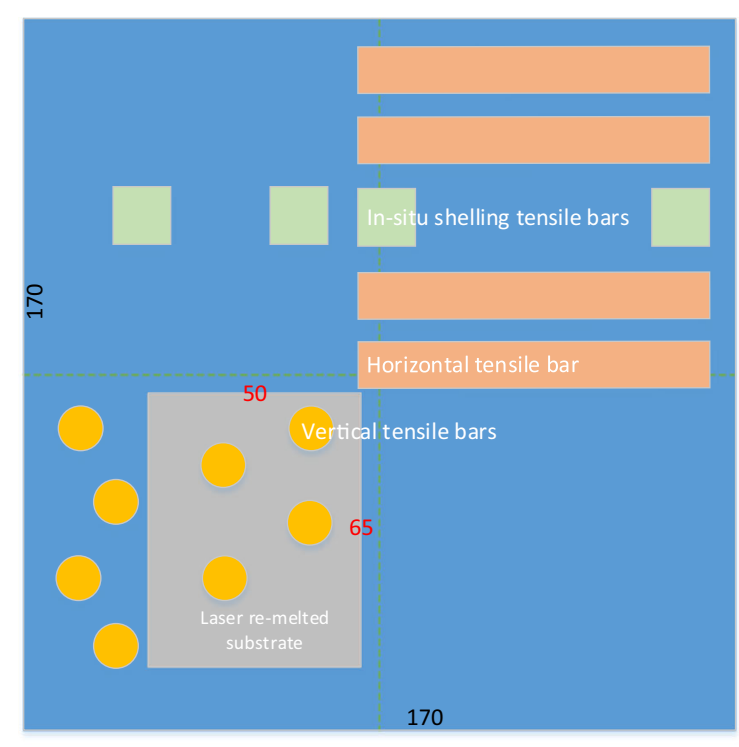

(a)

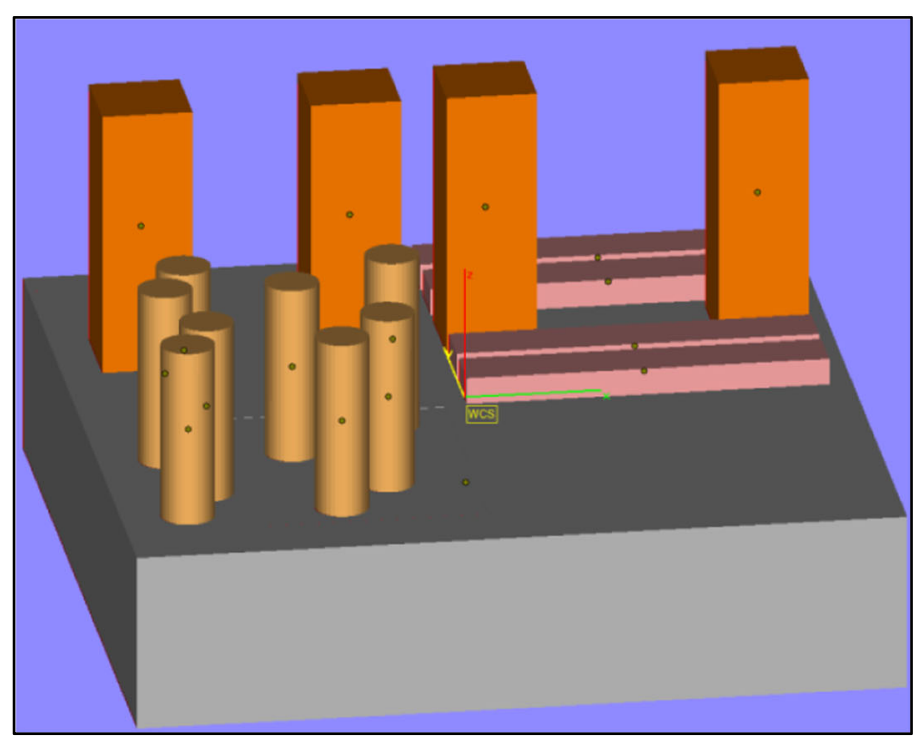

(b)

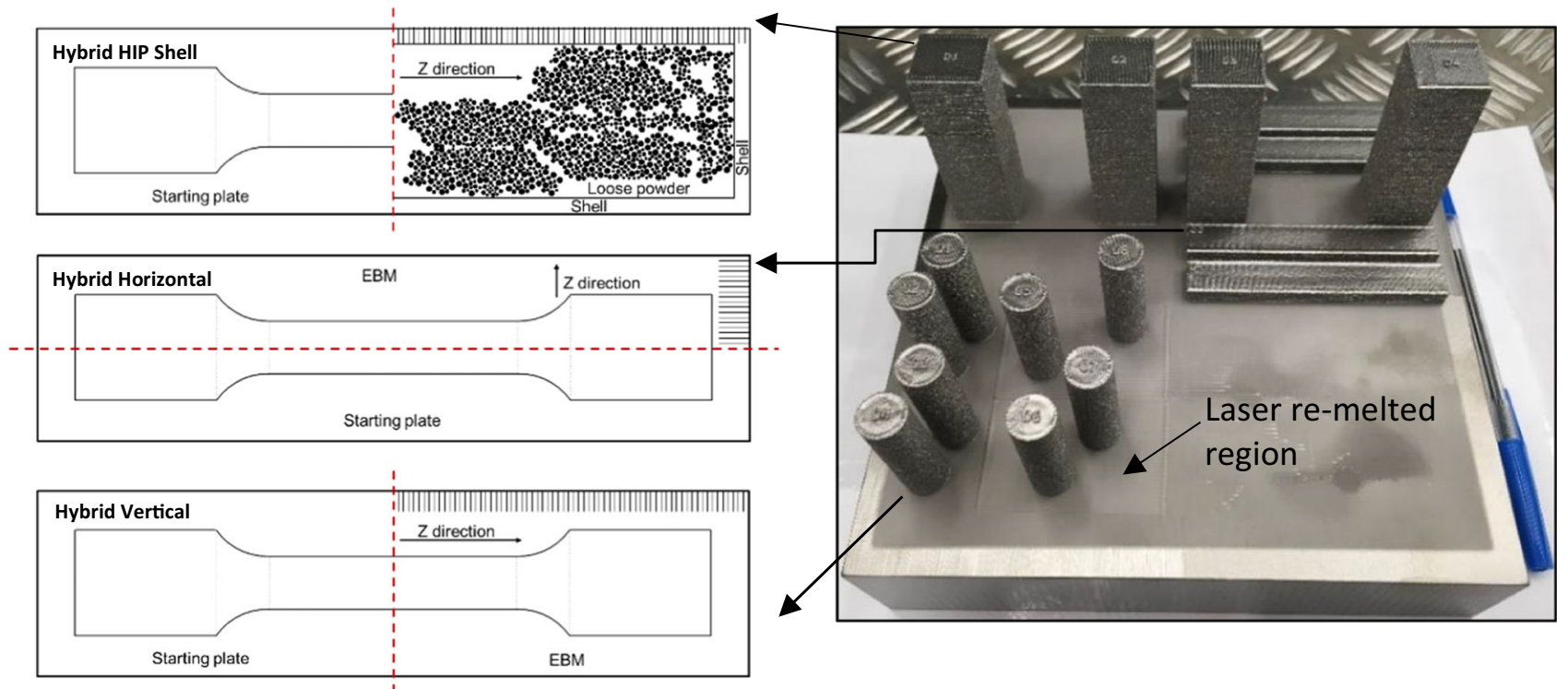

(c)

(d)

Fig. 2-(a) DOE 2 substrate design with tensile bar descriptions. (b) Magics 3D snap-shot of $40 \mathrm{~mm}$ starting plate and tensile bars location before the E-PBF build. (c) Schematic of the tensile bars and their characteristics manufactured (left); (d) DOE 2 completed build with all tensile specimens manufactured on $40-\mathrm{mm}$-thick $\mathrm{Ti}-6 \mathrm{Al}-4 \mathrm{~V}$ starting plate.

capture. After following the Mandil et al. technique ${ }^{[2]}$ of capturing the transition $\mathrm{T}$ from the heated area to the bottom region and waiting for the heat to transfer to the bottom, we decided to change the technique due a lack of efficiency. Based on our practical experience, the preheating phase was manually stopped above $700{ }^{\circ} \mathrm{C}$ to allow the build to commence.

\section{B. Influence of Beam Focus}

Beam focus (BF) measurements were carried out to better understand the changes and properties of the beam between the three different conditions used during DOE 1 (0 to 9 to $19 \mathrm{~mA})$. Four specimens as per condition, as Figure 3(a) partially shows, were manufactured. Beam size, line overlap, electron beam penetration into the starting plate and $X-Y$ axis surface roughness were cross compared between the BF conditions. A study of the variables was carried out taking the average of at least three samples of each condition. All analysis was performed using OM and SEM.

Top OM surface pictures of the specimens (Figure 3(b)) were taken to compare the beam size achieved on the top layer. Figures 3(c) through (e) show the comparison of the taken measurements, where a similar overlap between specimens of $\sim 200 \mu \mathrm{m}$ was observed. Slightly bigger beam size dimension in condition $\mathrm{BF} 19$, where a re-melted region of $\sim 650 \mu \mathrm{m}$ was 
observed, which is $\sim 40 \mu \mathrm{m}$ bigger than the melting achieved from BF 0 and 9. The last melt line of the cuboid's top surface was bigger in BF 19 condition due to an increased size of the defocused beam, which has a larger energy distribution that allowed a wider melted surface. ${ }^{[12]}$ BF 0 and 9 show a similar beam width condition, which can be connected to a sharper beam spot size achievable with the Arcam A2XX electromagnetic coils and a consequent reduction in width if compared to the defocused BF 19 condition (similar studies and results can be found in References 13 and 14 .

It is possible that the beam overlap of $200 \mu \mathrm{m}$, fixed from the machine settings, was confirmed between the $\mathrm{BF}$ parameters. The pictures display a different surface distribution between the different BF conditions, where their waviness was decreased from BF 0 to BF 19. To better understand the results, a top middle surface area of $2 \mathrm{~mm}^{2}$ investigation was performed to capture the surface roughness $(\mathrm{Sa})$ difference between samples. An average result of three samples of each condition was taken. As shown in Figure 4, average surface roughness values of $15.35,17$, and $10.52 \mu \mathrm{m}$ were obtained from 0 to 9 to $19 \mathrm{BF}$, respectively. BF 0 and 9 show a very close connection as demonstrated in the previous BF observations. The reduced roughness measured from BF 19 can be explained by a factor of energy density distributed on the surface. In fact, having a larger beam size with less energy density may result in less turbulence during the melting of the material with a smoother solidification phase, which decreases the surface roughness of the solidified powder. The results captured can be referred to top surface $\mathrm{Sa}$ measurements found in References 15 and 16.
Beam penetration was captured measuring the depth of the dilution into the starting plate after polishing the samples along the building direction, which can also be termed melting or fusion zone. The interested zone has a continuous linear dilution along the substrate in the hatch region. The measurements shown in Figure 4 highlighted an average of $\sim 150 \mu \mathrm{m}$ for the 0 and $9 \mathrm{BF}$ condition and a penetration of $\sim 110 \mu \mathrm{m}$ for the defocused $19 \mathrm{~mA}$ condition. The lower dilution of BF 19 can be connected to the reduced energy density with a defocused beam, with a consequent reduction in energy density and dilution as reported above. Despite this, the interface between the starting plate and the first layer has the same microstructural bonding independent of the $3 \mathrm{BF}$ conditions used. Similar hybrid studies ${ }^{[2,11]}$ have shown a good bonding interface between $\mathrm{Ti}-6 \mathrm{Al}-4 \mathrm{~V}$ to $\mathrm{Ti}-6 \mathrm{Al}-4 \mathrm{~V}$ and Inconel 718 to $316 \mathrm{~L}$ stainless steel.

\section{Microstructure and Microhardness of Hybrid Fusion Zone}

Metallurgical analysis was performed in the bonding region of the substrates where the melting penetration achieved in the "contour theme" zone reached more than $200 \mu \mathrm{m}$ on all specimens in a region that is $\sim 0.7$ to $0.8 \mathrm{~mm}$ from the side wall. As shown in Figure 5, two beam lines fuse the contour region using two different beam energy densities and speeds, which resulted in the internal contour line having higher dilution depth compared to the external one. The contour theme zone reached a maximum dilution of more than $200 \mu \mathrm{m}$ on all specimens in a region of $\sim 0.7$ to $0.8 \mathrm{~mm}$ from the side wall. A constant linear penetration of the AMed

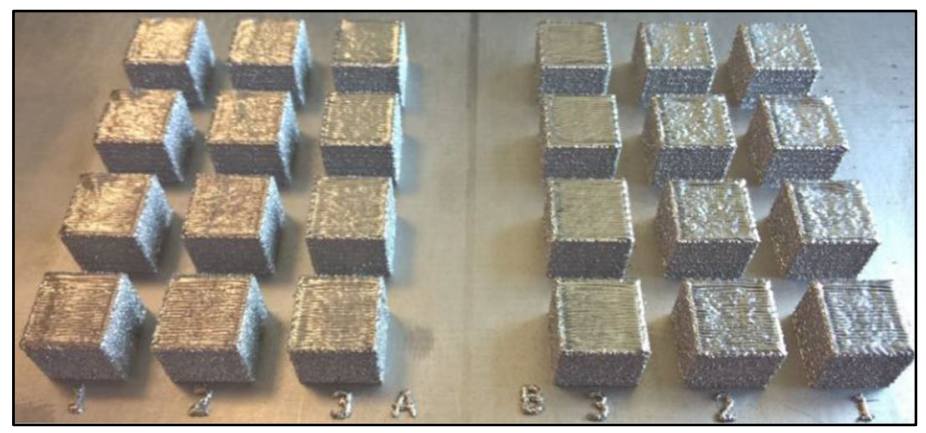

(a)

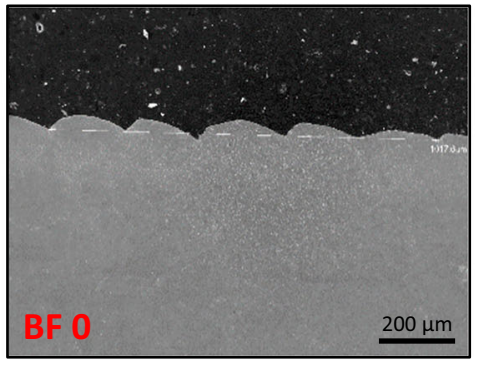

(c)

(d)

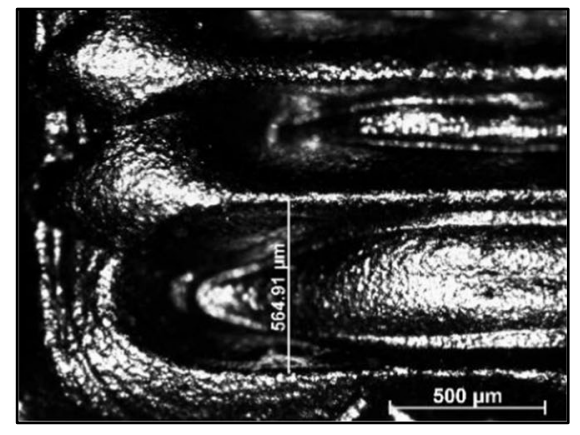

(b)

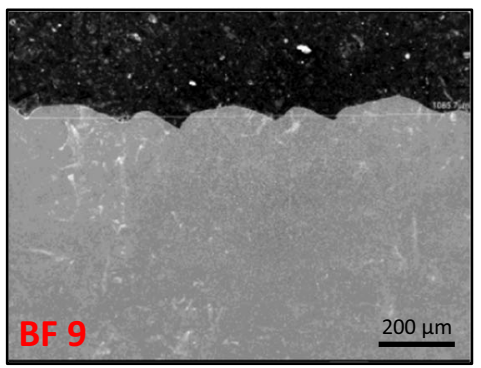

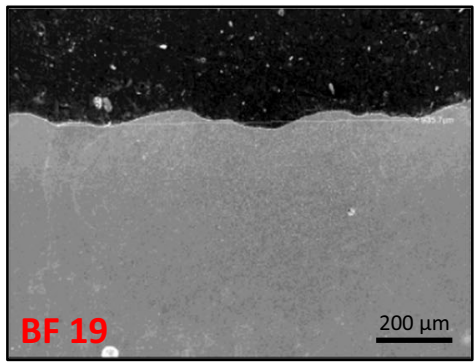

(e)

Fig. 3 - (a) Close picture of half of the cuboids analyzed during the BF investigation, and (b) A2 top line scan measurement captured with OM. SEM cross-section images of $(c) \mathrm{A} 1,(d) \mathrm{A} 2$, and (e) A3 top surface for relative overlap measurements. 


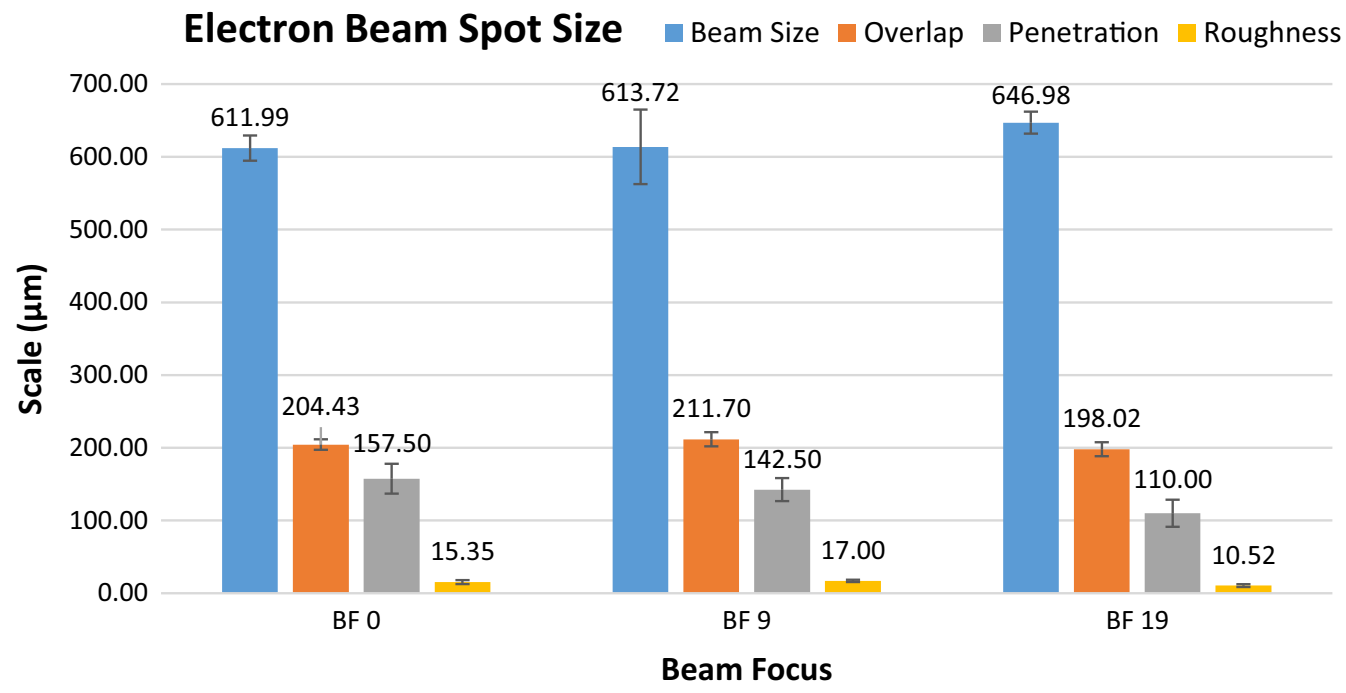

Fig. 4-Histogram showing influences of $\mathrm{BF}$ on the E-PBF Ti-6Al-4V builds.

material into the substrate with $\sim 130 \mu \mathrm{m}$ (specimen B2) that linearly happens along all the fusion region fused by the "melting theme" was observed, which is almost double scale of the E-PBF layer thickness. The fused material into the substrate is a mixture of the powder spread on the first layer and the re-melting of the substrate. Similar microstructure was noticed in all three beam conditions applied and the substrate pre-treatments. The variations in $\mathrm{BF}$ and substrate pre-treatment did not influence the re-melted region significantly.

As visually inspected, lack of fusion at $\sim 0.7 \mathrm{~mm}$ above the starting plate along the mid-region of the layer was noticed, which was due to a process instability (potential powder spreading inconsistency issues ${ }^{[17]}$ ). To solve this issue, it is necessary to run a HIP cycle to close the pores and homogenize the microstructure. ${ }^{[18]}$

Figure 6(a) shows columnar grains starting from the fusion area which represent the typical prior $\beta$-grain observed in PBF technologies. ${ }^{[19]}$ The $\alpha+\beta$ dual-phase microstructure was noticed all along the structure where prior $\beta$-grains were grown following the vertical direction of cooling. ${ }^{[20,2 \mathrm{~T}}$ Heat-affected zone (HAZ) was shown below the fusion zone with a minimal impact on the starting plate quantified as less than half a millimetre (Figure 6(b)).

The bonding region does not show neither porosity nor micro-cracks. A smooth transition was observed along the solidified boundary area as shown in Figure 7(a). The boundary line is well defined between the coarse substrate microstructure and the refined basket-weave microstructure, where a rounded dilution from the electron beam impact is observed. Figure 7(b) shows the interface between the AMed part and the laser re-melted substrate; and it was noticeable that both surface regions have refined grains and strong microstructural bonding which may increase the fusion zone strength and reduce potential cracks in the additive/substrate intersection. The interface below the re-melted region does not show bonding imperfections. Figures 7(c) and (d) show the growth of $\alpha$ grain boundaries from the HAZ, growing into the re-melted region of the component. They were generated during an increase in temperature of the substrate which reached higher than $1000{ }^{\circ} \mathrm{C}$, above the $\beta$ transus, where main $\beta$-grains recrystallize. It is suggested that the $\beta$-grains generated in the HAZ region penetrate through the re-melted zone and continue their growth in the first AMed layer, which means that a strong bonding interface was generated. Desirable interface fusion was observed in all the specimens which showed very similar bonding interface.

Figure 8 illustrates the location of indents captured from a sectioned $X-Z$ plane in the middle of $Y$ thickness, using a load of $200 \mathrm{~g}$. They run from +0.4 $\mathrm{mm}$ above to $-0.7 \mathrm{~mm}$ below the fusion area in order to cover the hardness changes between the AMed part and the starting plate/substrate after the addition of the materials on top. It is seen that the AMed region yields a microhardness value of $\sim 390 \mathrm{HV}$ which then increases to $\sim 400 \mathrm{HV}$ close to the fusion region (which is similar ${ }^{[16]}$ or slightly above the literature values ${ }^{[22]}$, identified at around the $0 \mathrm{~mm}$ bonding region. The increase in hardness is probably due to the rapid cooling rate achieved by dissipating the heat to the starting plate. This helps to rapidly solidify the first layers with a consequent reduction in $\alpha$ lath width and an increase in microhardness. However, the contamination of material explained in Reference 23 may also contribute to the change in hardness located in the first few layers. The HAZ, quantified after the fusion region, extends around half a millimetre below the bonding region. It is featured by a high level of hardness close to the fusion region, 


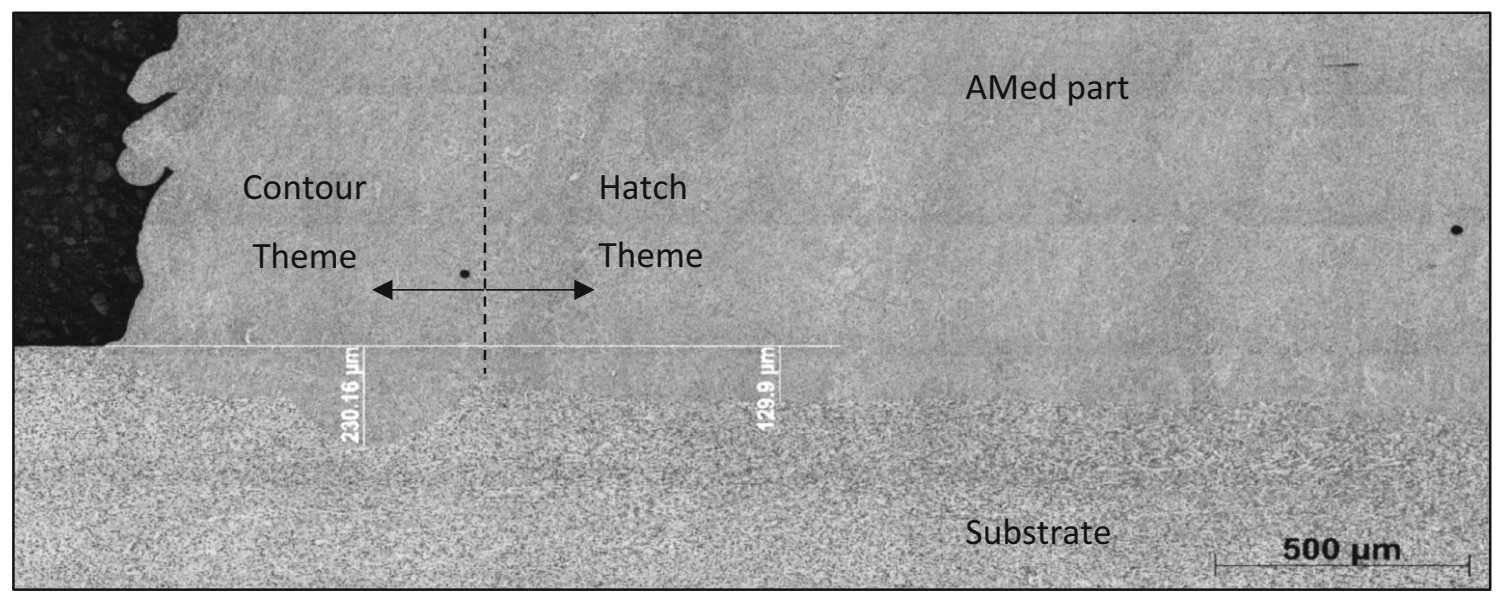

Fig. 5- OM image showing fusion zone between substrate and deposited region of the etched B2 cube.

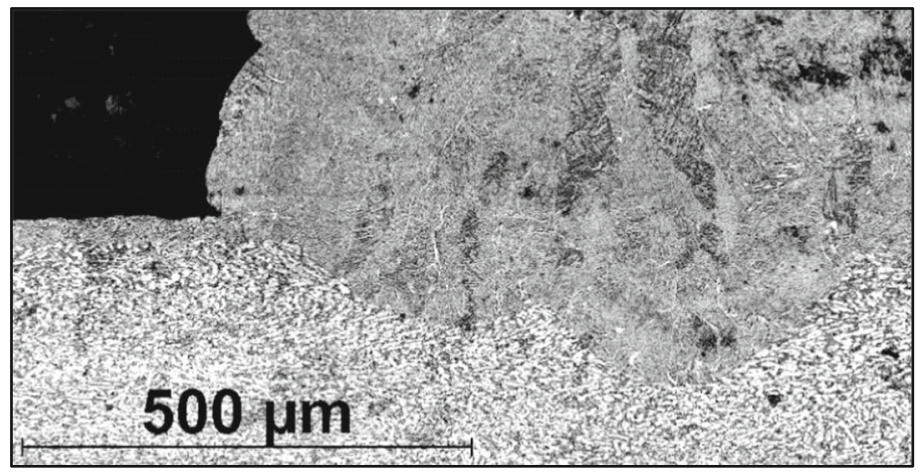

(a)

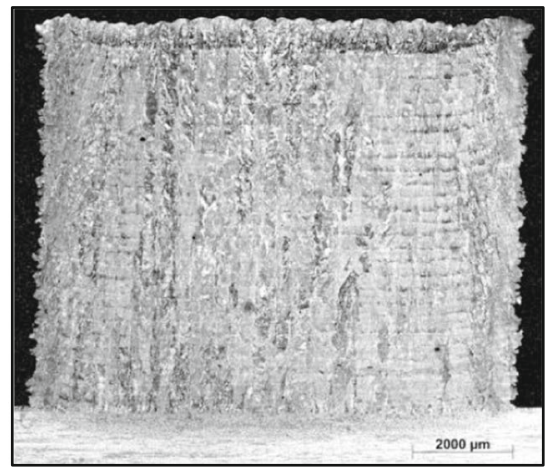

(b)

Fig. 6- OM images showing electron beam penetration and typical columnar-grained microstructure from (a) the laser re-melted D3 substrate and $(b) \mathrm{D} 2$ part.

where the microstructure exhibited a refinement of grains while heating up and cooling down the material, which was decreased proportionally to the HAZ and its heating influence. The Ti-6Al-4V starting plate, without thermal influence from the AM process, has a microhardness value of just around $350 \mathrm{HV} .^{[24]}$ The microhardness of the starting plate captured during DOE 1 was assumed as a constant for the DOE 2. Moreover, the differences in hardness are probably due to the high oxygen content within the powder which increases the hardness meanwhile reducing the material ductility. ${ }^{[25]}$

\section{Tensile Properties of hybrid E-PBF AM of $\mathrm{Ti}-6 \mathrm{Al}-4 \mathrm{~V}$}

A starting plate of $40 \mathrm{~mm}$ thick was used as a substrate to build tensile bars during DOE 2. Four equally divided surface conditions were maintained as the first $10-\mathrm{mm}$-thick starting plate experiment. Four tensile bar samples for each orientation and condition were designed to better understand the bonding between the AMed part and the substrate.
Figure 2 shows the tensile strategies adopted during the manufacturing of the tensile bars and a representation of the completed build. Horizontal and vertical oriented bars were manufactured from the starting plate. The scope of the tests was focused on keeping the interface in the middle region of the gauge length in order to better understand the strength of the bonding and its mechanical properties. Two batches of four vertical tensile bars were manufactured to capture the tensile properties with conventional and laser re-melted substrates to understand potential mechanical differences in the bonding region. Horizontal tensile specimens were built in a cuboid shape with the aim of maintaining the bonding region along the tensile bar length. Four vertical shells with trapped, loose, pre-sintered powder were manufactured with the intention of solidifying the enclosing powder through a post HIPping treatment that enabled the complete solidification of the powder encapsulated in the shell. This method allows bonding between the substrate, the powder solidified, and the E-PBF shell after the completion of the HIP treatment. Table III compiles the tensile results 


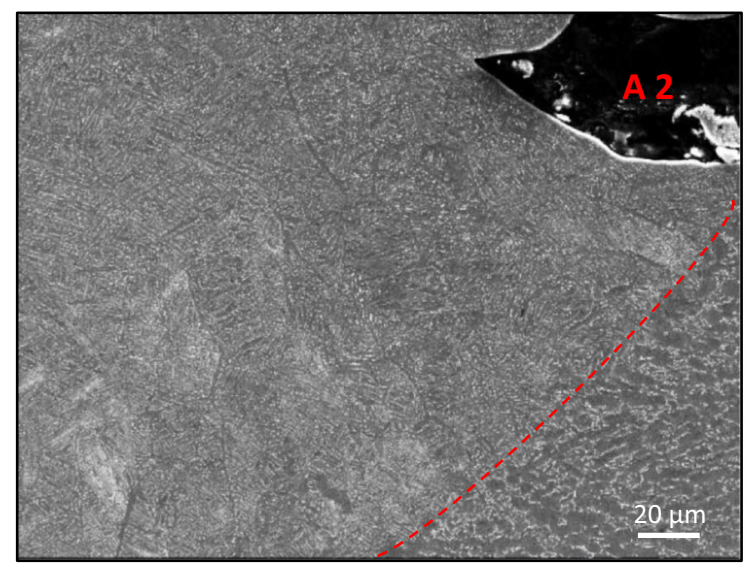

(a)

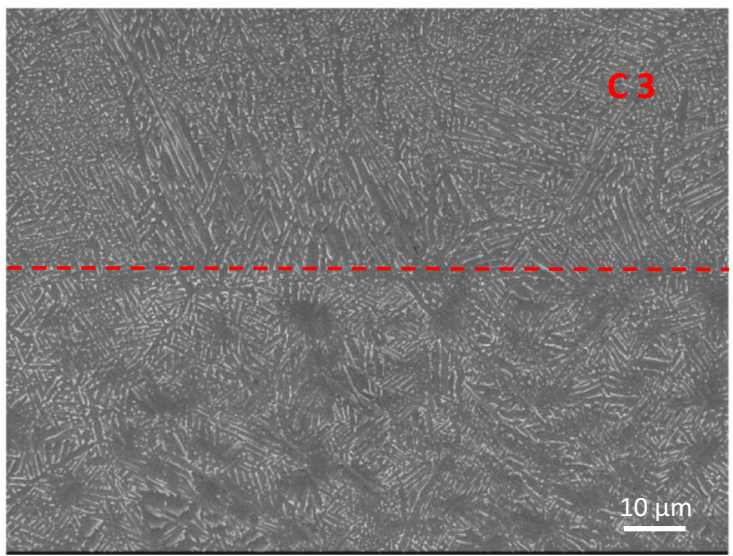

(c)

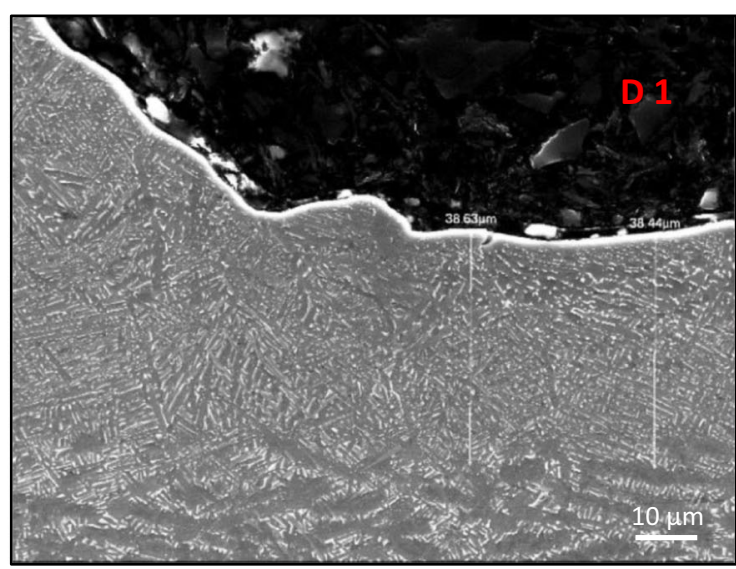

(b)

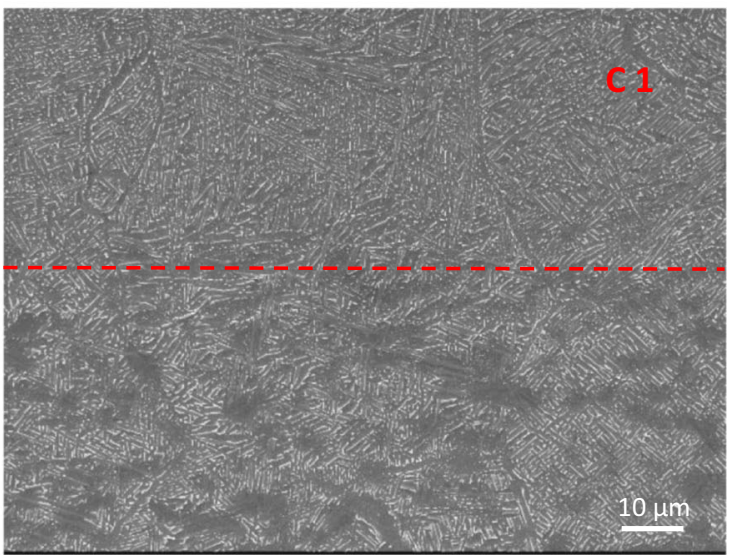

(d)

Fig. 7-Fusion zone of bottom left $X-Z$ A2 sample section $(a)$, laser re-melted bottom left $X-Z$ D1 sample section $(b)$, central fusion interface of sample $\mathrm{C} 3(c)$, and $\mathrm{C} 1(d)$ with main $\beta$-grains growing through the fusion zone.

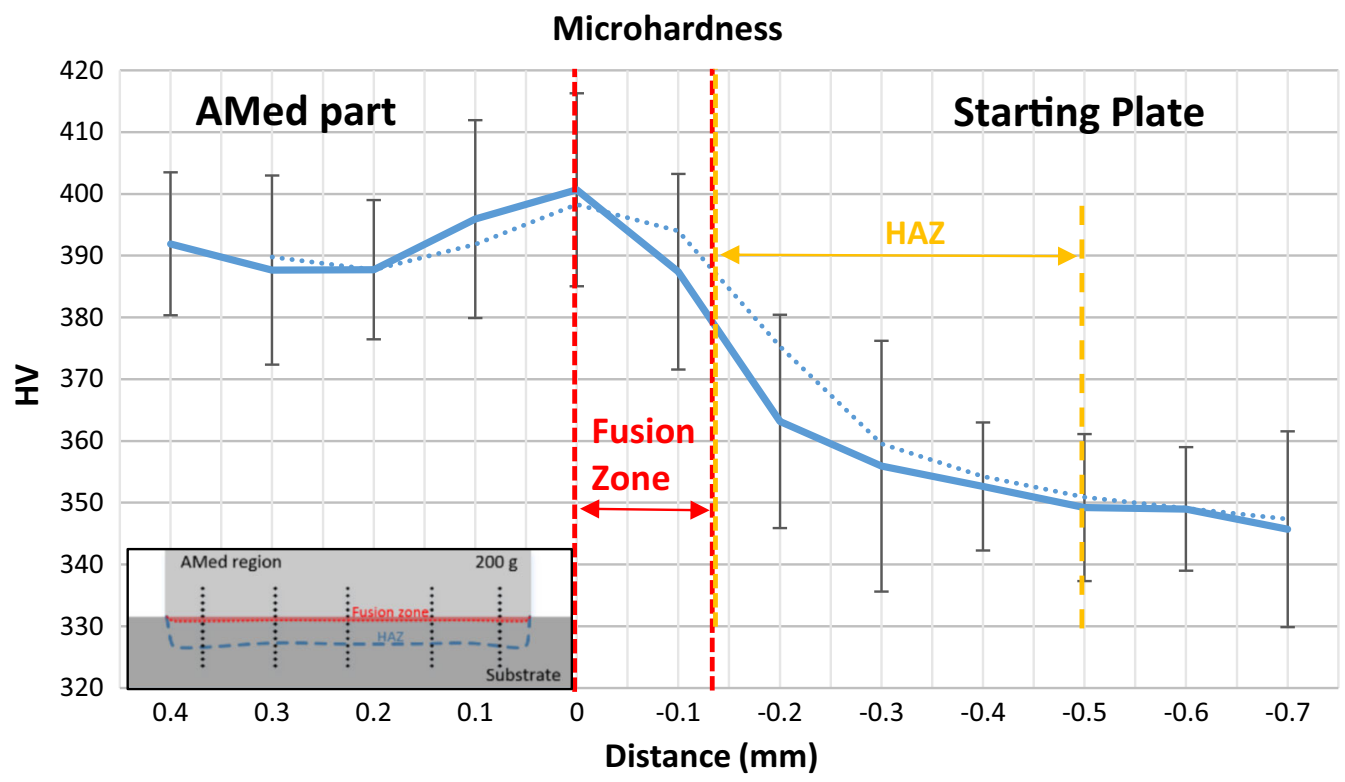

Fig. 8-HV microhardness profile across the AM build and substrate regions. 
Table III. Tensile Bar Results

\begin{tabular}{|c|c|c|c|c|}
\hline & UTS (MPa) & $0.2 \mathrm{YS}(\mathrm{MPa})$ & Plastic Elongation (Pct) & \\
\hline Hybrid Horizontal \#1 & 1045 & 960 & 15.2 & \\
\hline Hybrid Horizontal \#2 & 1056 & 955 & 14.1 & $*$ \\
\hline Hybrid Horizontal \#3 & 1049 & 963 & 16.1 & \\
\hline Hybrid Vertical \#1 & 1030 & 892 & 14.4 & \\
\hline Hybrid Vertical \#2 & 1037 & 923 & 6.4 & + \\
\hline Hybrid Vertical \#3 & 1032 & 907 & 6.1 & + \\
\hline Hybrid Vertical \#4 & 1035 & 917 & 6.7 & + \\
\hline Hybrid Vertical \#5 & 1038 & 901 & 4.5 & + \\
\hline Hybrid Vertical \#6 & 1034 & 894 & 6.1 & + \\
\hline Hybrid Shelling Vertical \#1 & 1009 & 871 & 5.7 & + \\
\hline Hybrid Shelling Vertical \#2 & 1011 & 872 & 6.1 & + \\
\hline Hybrid Shelling Vertical \#3 & 1007 & 868 & 4.7 & + \\
\hline Substrate \#1 & 991 & 924 & 16.6 & + \\
\hline Substrate \#2 & 1000 & 922 & 15.9 & + \\
\hline Substrate \#3 & 997 & 931 & 16.9 & + \\
\hline
\end{tabular}

*Indicates if the specimen broke outside the middle 50 pct of the gauge length.

+ Indicates if the specimen broke outside of the gauge length.

of the total 15 specimens. Pictures of the manufactured raw and machined samples are shown in Figure 9.

Figure 9(a) summarizes all the tensile properties completed during the mechanical tests. All the results obtained for ultimate tensile strength (UTS) and yield strength (YS) were classified above the standard required in AM Ti-6Al-4V, ${ }^{[26]}$ and elongation showed different results between specimens. The Hybrid horizontal tensile bars (Figure 9(b)) achieved superior mechanical properties. The elongation measured was above 14 pct for all specimens which is comparable with References 27 and 28 and considered good properties using an E-PBF system. However, some specimens (Figures 9(c) through (e)) showed ductility below the ASTM standard of 10 and $>15$ pet obtained with wrought material. ${ }^{[29]}$ Figure 10 shows the fracture surface captured with SEM at low magnifications, where it is possible to distinguish the bonding line between the AMed region and the substrate (Figure 10(a)). This was identified through the circular gas porosity (Figure 10(b)), which are residual gas pores trapped into the layers. No gas pores were detected in the substrate as previously inspected. Ductile behavior was observed from the typical dimples ductile fracture across all fracture surfaces of the specimen. The crack initiation site is located inside the starting plate region which resulted with lower UTS, YS, and microhardness compared to the E-PBFed region, and it gradually propagates through the middle region of the specimens in both AMed and substrate material. All the specimens inspected showed similar fracture characteristics to each other. As reported by Qiu et al., ${ }^{[30]}$ when the axial load is normal to the interface, it is likely to have poor elongation properties as favorable crack initiation sites tend to initiate and propagate perpendicularly to the load direction. Figure 9(e) highlights the fracture occurring in the middle of the substrate region for the hybrid vertical build, where it is shown that the plastic strains were mainly concentrated in that half during the tensile test and a "poor" elongation was obtained. Similar results were observed by Wang et al. ${ }^{[31]}$ where the hybrid substrate showed weakened conditions compared to the E-PBF built material which was consequently reflected during mechanical tests.

The hybrid vertical tensile samples show a ductile fracture with satisfactory tensile and yield strengths, and an elongation around or below 6 pct excluding sample \# 1 , which are less than the 10 pct required by the ASTM standards. Sample \# 1 was the only specimen which broke in the middle region of the gauge length, with an elongation of 14.4 pct. Figure 11 shows the ductile surface fracture and its crack initiation site. It is probably initiated from a pore located in the AMed area close to the surface which then propagated across the starting plate material, observed in the absence of pores normally seen with AMed parts. However, tensile and yield strengths are equivalent to the other five vertical samples, which could be related to similar mechanical properties with a better elongation. The other vertical samples broken outside the gauge length region of the specimen, as shown in Figure 9(e), all show a failure in the starting plate region. All the samples analyzed had a crack initiation site starting from the specimen surface and all showed similar fracture behavior. No differences were noticed between samples built on the normal substrate and on the laser re-melted condition. The different starting plate surface conditions did not affect the tensile properties.

In-situ shelling hybrid tensile bars were also performed after HIP treatment to consolidate the powder trapped inside the shell before being machined to the final tensile geometry. Before HIPping, shrinkage estimations were considered to allow enough material to generate half of the tensile bar from the AMed region. The bonding region between the three areas can be observed in Figure 12, where all seem to be well fused and no pores or lack of fusions were observed. Distorted prior $\beta$-grains are observed in the AMed region (Figures 12(a) and (b)) caused by the shrinkage that took place during the HIPping process. No cracks 


\section{Tensile Properties}

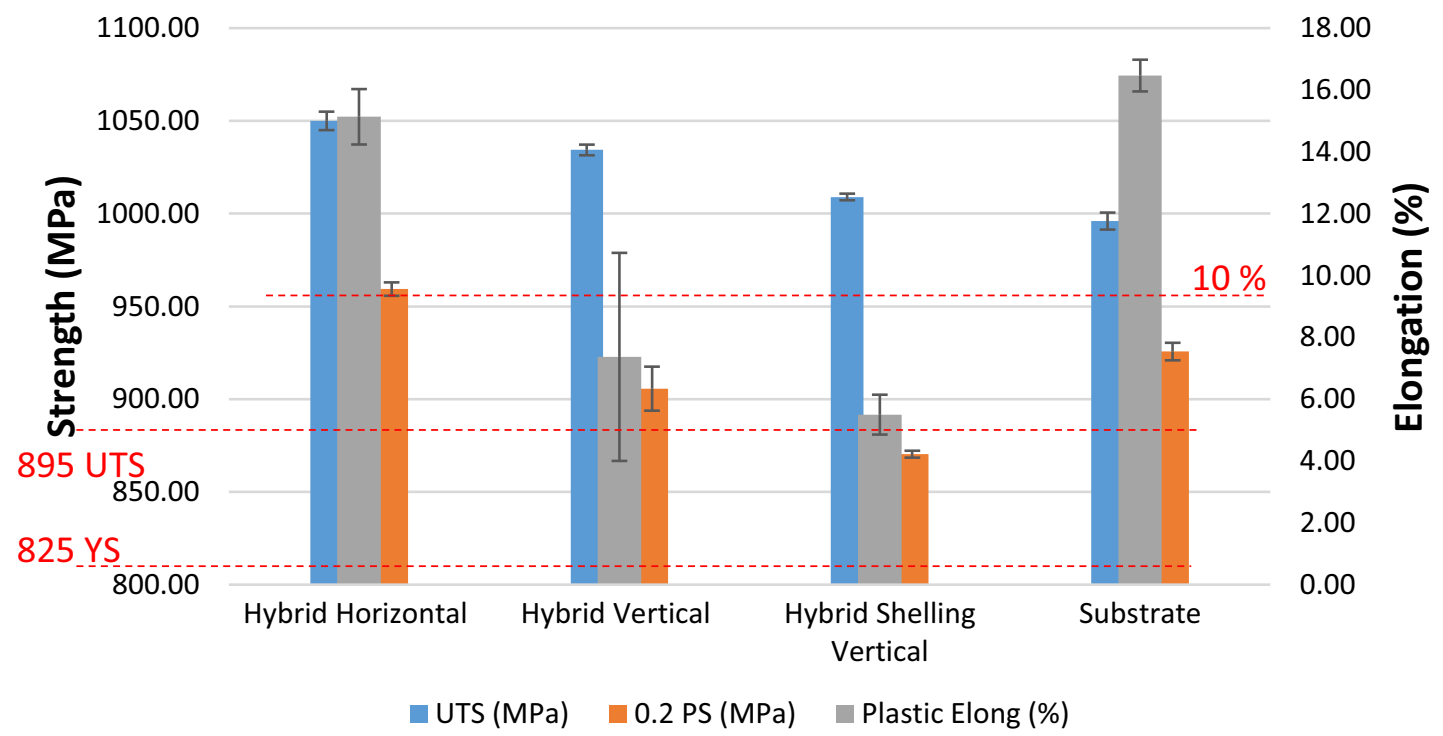

(a)

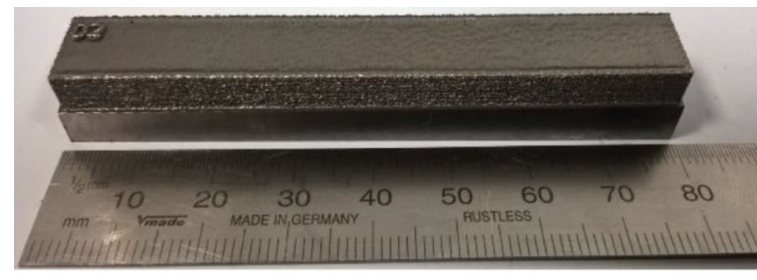

(b)

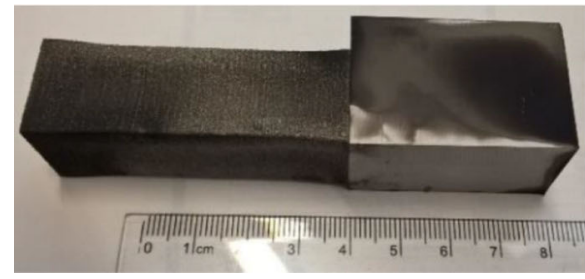

(d)

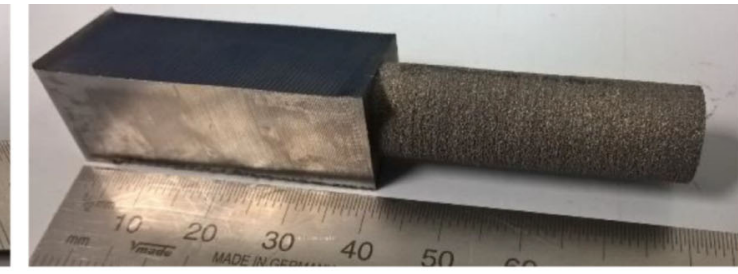

(c)

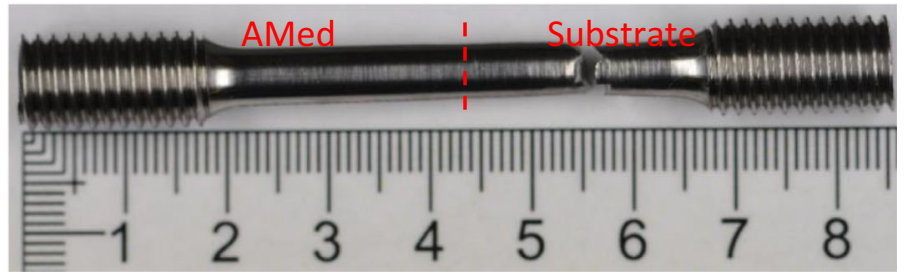

(e)

Fig. 9-(a) Histogram of tensile properties for tensile bars compared to ASTM F2924 - 14 Standard. Graphs of (b) horizontal, $(c)$ vertical, and (d) vertical in-situ shelling HIPped tensile bars before being machined. (e) Graph showing fractured hybrid vertical \#3 tensile bar after tensile testing.

or defects were observed in the bonding and join interfaces which allowed for a successful HIPping cycle. The HIP cycle generated a fully equiaxed structure in the loose powder region (Figure 12(c)), and an increase in $\alpha$ lath thickness in the E-PBF fabricated region. Figure 13(a) presents fracture surface and ductile breaking behavior outside the gauge length region obtained from sample \#1. The homogeneity of the dimples noticed along the entire fracture surface (Figure 13(b)) does not clarify which region of the specimens failed, even if an optimized powder HIP cycle can achieve better properties than the conventional casting and forging routes. ${ }^{[32]}$ The reduction in mechanical properties shown in Table III could be attributed to the post HIPping treatment performed on the samples which reduced the mechanical properties of the starting plate, lowering the mechanical values observed with the vertical tensile specimens. However, differences in mechanical properties between the HIPped and substrate region can originate an early failure or a reduced elongation. An investigation on cross section could be performed to better understand the breaking region and its properties.

\section{CONCLUSIONS}

This work investigated a hybrid AM solution using the substrate as an integrated part of the final component, as a feasibility study. Literature was used to guide the experiment, where the standard parameters were kept as a guideline for the experiments. Two sets of 


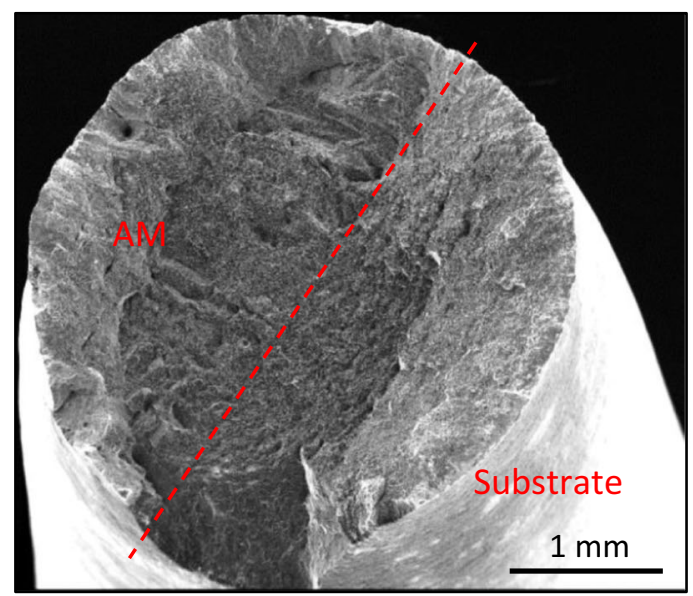

(a)

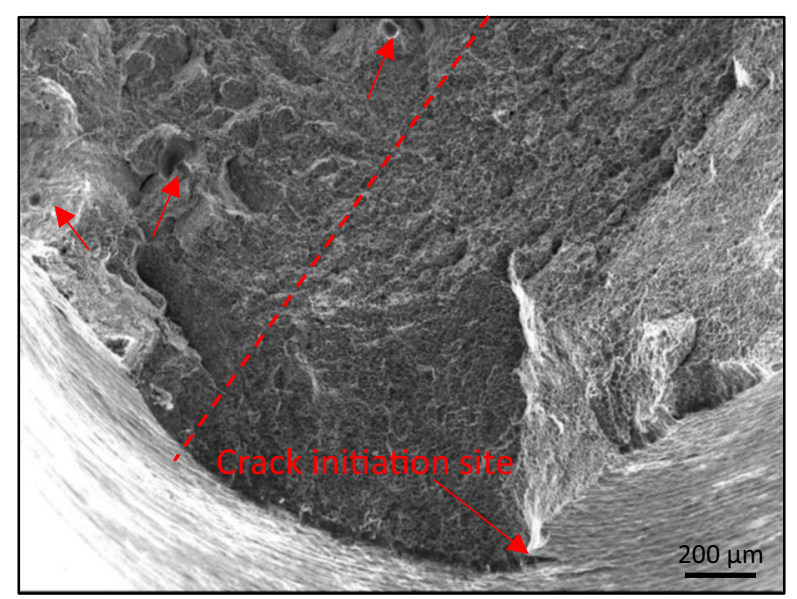

(b)

Fig. 10-SEM tensile surface fracture analysis of hybrid horizontal \#1 sample. (a) Full image of the AMed part on the substrate and (b) the enlarged view. Arrows show the porosity generated during the AM of the material and the crack initiation of the specimens (b).

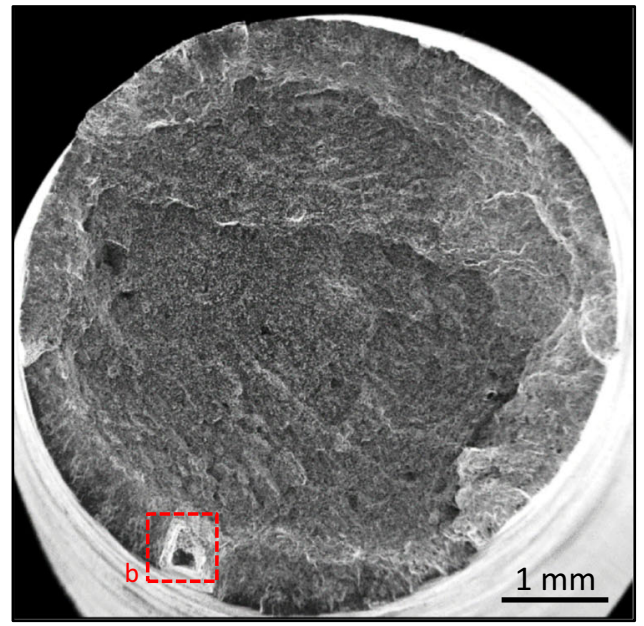

(a)

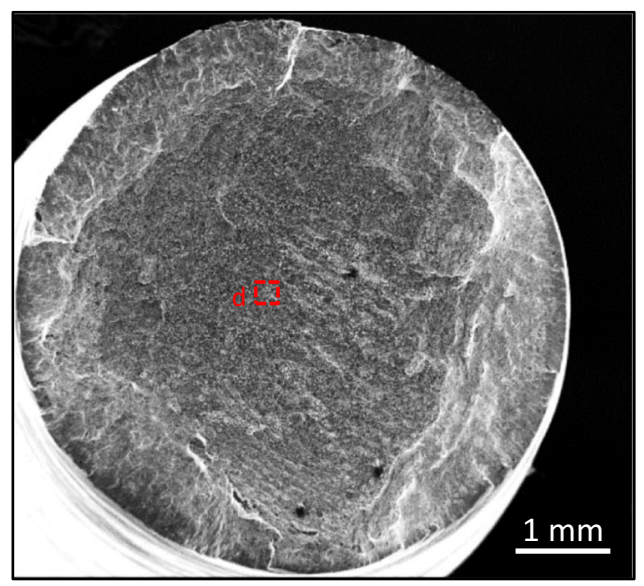

(c)

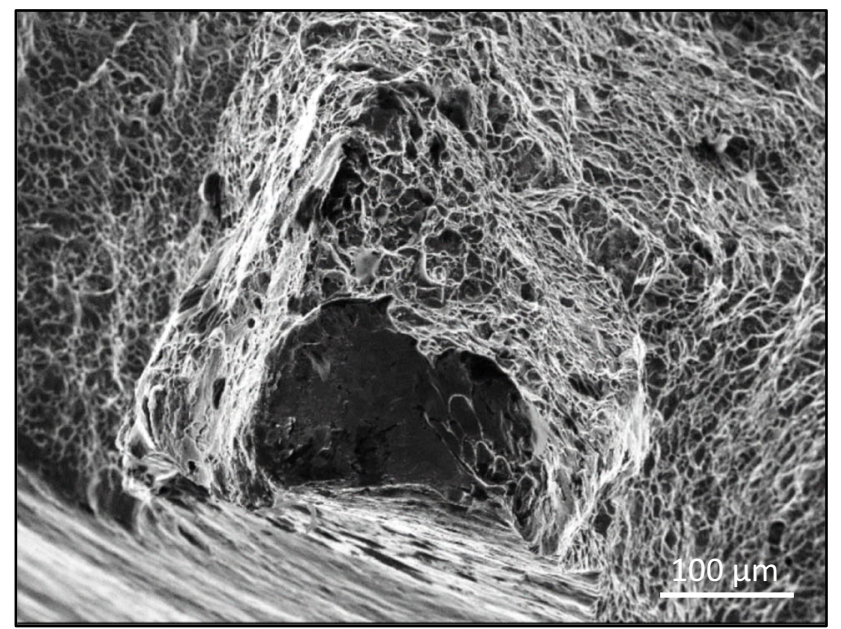

(b)

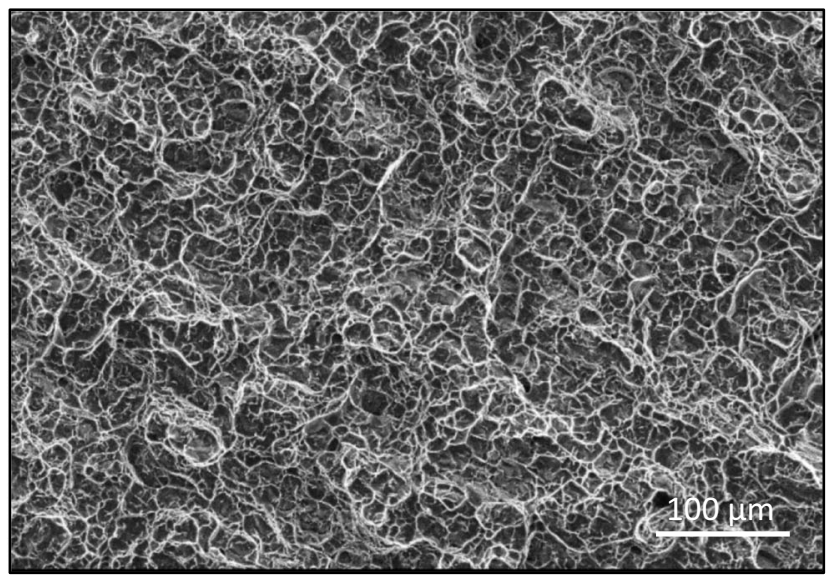

(d)

Fig. 11-(a) SEM fractography of hybrid vertical \# 1 surface fracture sample and $(b)$ its crack initiation pore. $(c)$ Hybrid vertical \# 2 surface fracture sample and $(d)$ its ductile dimpled surface. 


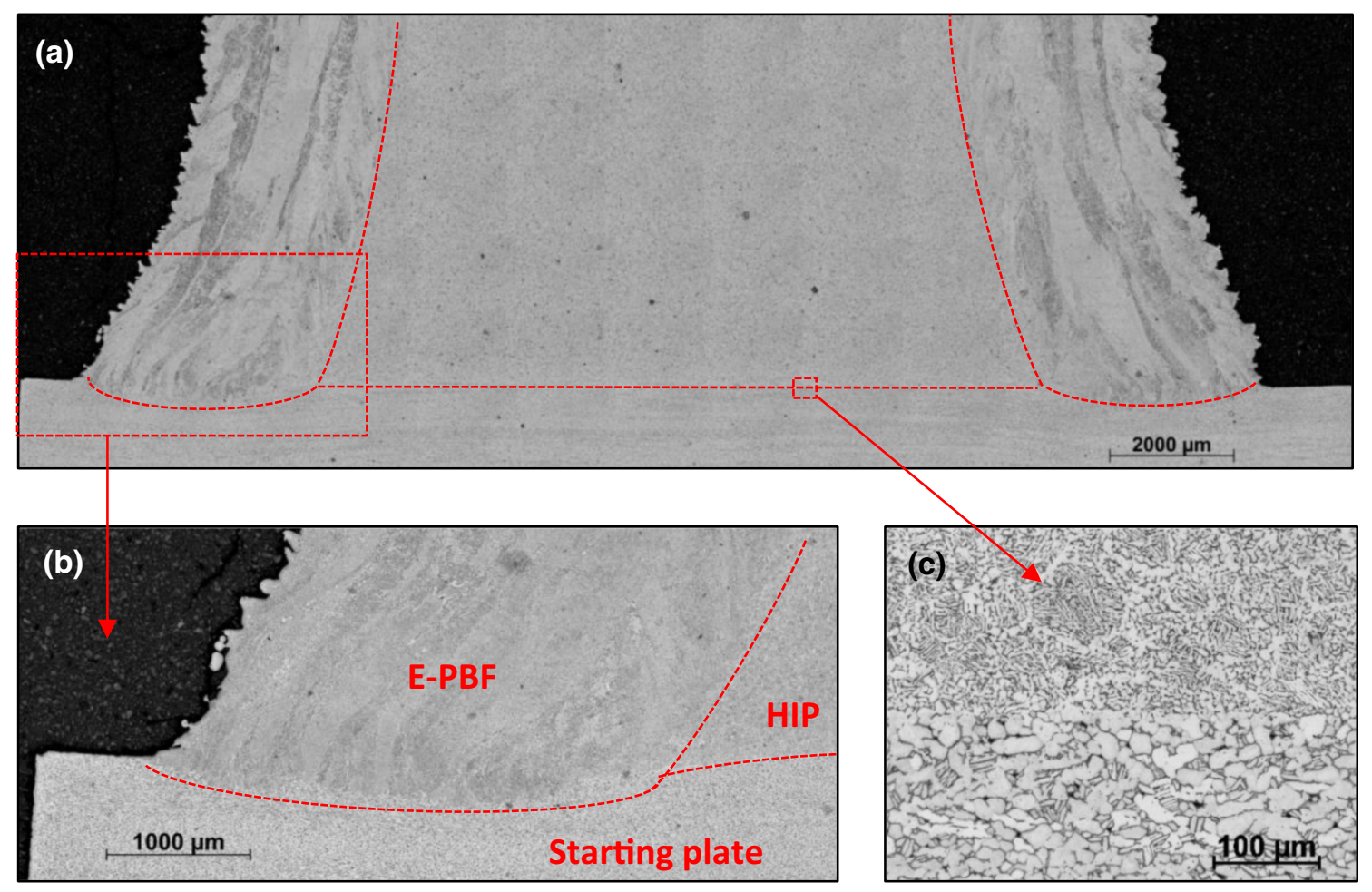

Fig. 12- (a) OM $X-Z$ cross section of \#4 sample, intersection lines between the E-PBF built, HIP consolidated, and the substrate materials. (b) Enlarged view of the three distinct materials in (a). (c) microstructure at the interface region between the consolidated material and the substrate.

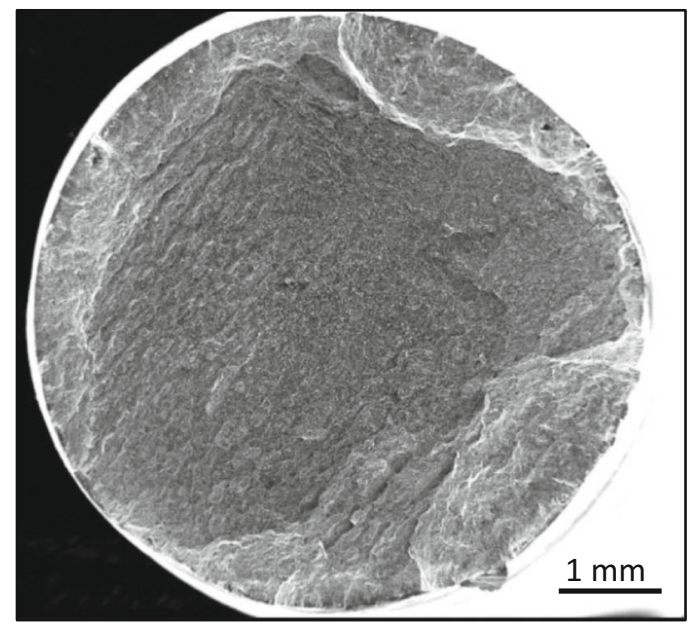

(a)

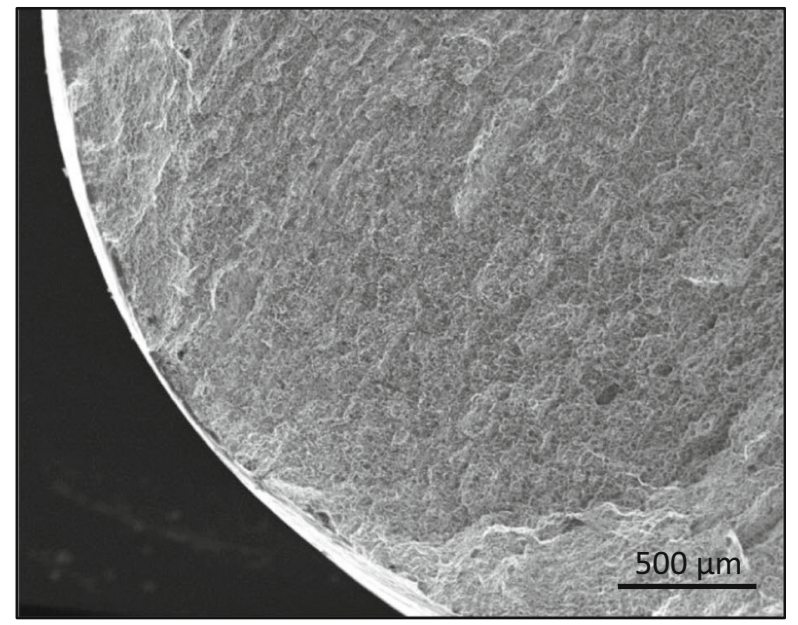

(b)

Fig. 13-(a) SEM fractography of the in-situ hybrid vertical \# 1 sample and (b) its ductile fracture behavior.

experiments with two different Ti-6Al-4V starting plate thicknesses (10 and $40 \mathrm{~mm}$, respectively) were conducted to understand the dilution and metallurgical properties in the bonding region using different $\mathrm{BF}$ and surface treatment. The second set of experiment was developed to better understand the mechanical performance of the bonding interfaces with different manufacturing approaches and orientations. Four different substrate conditions were used to better understand potential influences on the interface between the starting plate and the first few bonded layers.
1. During the DOE investigation, it was understood that by keeping the substrate temperature up to 720 ${ }^{\circ} \mathrm{C}$ for a long time, just the laser re-melted surface was kept with the initial properties as a fused region. The peened region and the Kroll's etched area were stress relieved and cleaned up from the electrons shot on the surface and the maintained high temperature. A linear dilution region was noticed in all conditions tried in DOE 1 , which generated a good bonding interface between the first E-PBFed layer and the starting plate. Small 
differences in dilution across the different BF were observed due to differing energy distribution.

2. In the HAZ region, prior $\beta$-grains were grown from the substrate to the AMed region, which demonstrated excellent bonding between the substrate and the first few layers. A finer superficial microstructure was observed between the laser re-melted substrate region and the edge of the AMed area. The high-strength bonding may help reduce interface cracks in the welding toe region, but more studies are needed to better understand its properties and potential benefits.

3. BF influence analysis exposed different behaviors in the beam between 19 and 0 to $9 \mathrm{~mA}$, where the refined 0 and $9 \mathrm{~mA}$ had a higher energy density and a consequent increment in melt pool compared to the $19 \mathrm{~mA}$ ones. No relevant differences in bonding, porosity, or HAZ were noticed between the samples. A small improvement in top surface roughness was observed defocusing the $\mathrm{BF}$.

4. Microhardness and tensile properties results demonstrated that the hot-rolled and annealed starting plate had lower mechanical properties compared to the AM regions. Therefore, most of the mechanical specimens broke outside the gauge length area in the substrate region, apart from the horizontal bars which had a failure across the bonding region. Some of the ductility results were below the forged $\mathrm{Ti}-6 \mathrm{Al}-4 \mathrm{~V}$ values of $>15$ pct.

5. The hybrid shelling technique proved that it is possible to generate an enclosed shell with the substrate to be HIPped afterwards. Good bonding properties were observed between the E-PBF, starting plate, and powder HIPped interface. However, the elongation properties did not reach the level required for aerospace standards of 10 pct.

\section{ACKNOWLEDGMENTS}

The authors acknowledge financial support from AMAZE (Additive Manufacturing Aiming towards Zero Waste and Efficient Production of High-Tech Metal Products) project funded by the 7th Framework Programme of the European Commission (Contract FP7-2012-NMP-ICTFoF-313781). The Manufacturing Technology Centre (MTC) for the use of their facilities and technical and financial support provided along the project.

\section{AUTHOR CONTRIBUTIONS}

RT, DW conceived the project. EM generated the machine files and performed the builds. RT, DW, EM, and MA reviewed and technically supported the project along its evolution. RT performed optical imaging and led mechanical testing. RT, EM, and XPT led the results discussion and interpretation. RT, EM, and XPT paper writing.

\section{CONFLICT OF INTEREST}

On behalf of all authors, the corresponding author states that there is no conflict of interest.

\section{OPEN ACCESS}

This article is licensed under a Creative Commons Attribution 4.0 International License, which permits use, sharing, adaptation, distribution and reproduction in any medium or format, as long as you give appropriate credit to the original author(s) and the source, provide a link to the Creative Commons licence, and indicate if changes were made. The images or other third party material in this article are included in the article's Creative Commons licence, unless indicated otherwise in a credit line to the material. If material is not included in the article's Creative Commons licence and your intended use is not permitted by statutory regulation or exceeds the permitted use, you will need to obtain permission directly from the copyright holder. To view a copy of this licence, visit http://creat ivecommons.org/licenses/by/4.0/.

\section{REFERENCES}

1. K.A. Lorenz, J.B. Jones, D.I. Wimpenny, and M.R. Jackson: Solid Free. Fabr., 2015, vol. 53, pp. 96-108.

2. A. Hinojos, J. Mireles, A. Reichardt, P. Frigola, P. Hosemann, L.E. Murr, and R.B. Wicker: Mater. Des., 2016, vol. 94, pp. 17-27.

3. P. Kürnsteiner, M.B. Wilms, A. Weisheit, P. Barriobero-Vila, B. Gault, E.A. Jägle, and D. Raabe: Microsc. Microanal., 2017, vol. 23, pp. 694-5.

4. M. Simonelli, D.G. McCartney, P. Barriobero-Vila, N.T. Aboulkhair, Y.Y. Tse, A. Clare, and R. Hague: Metall. Mater. Trans. A., 2020, vol. 51A, pp. 2444-59.

5. X. Shia, S. Maa, C. Liua, Q. Wua, J. Lua, Y. Liub, and W. Shib: Mater. Sci. Eng. A., 2017, vol. 684, pp. 196-204.

6. M. Merklein, D. Junker, A. Schaub, and F. Neubauer: Phys. Procedia., 2016, vol. 83, pp. 549-59.

7. F. Scherillo, M. Liberini, A. Astarita, S. Franchitti, C. Pirozzi, R. Borrelli, P. Cirillo, A. Caraviello, A. Squillace, and L. Carrino: Procedia Eng., 2017, vol. 183, pp. 264-9.

8. L. Portolés, O. Jordá, L. Jordá, A. Uriondo, M. Esperon-Miguez, and S. Perinpanayagam: J. Manuf. Syst., 2016, vol. 41, pp. 65-75.

9. C.A. Terrazas, S.M. Gaytan, E. Rogriguez, D. Espalin, L.E. Murr, F. Medina, and R.B. Wicker: Adv. Manuf. Technol., 2014, vol. 71, pp. 33-45.

10. M.S. Hossain, J.A. Gonzalez, R.M. Hernandez, M.A.I. Shuvo, J. Mireles, A. Choudhuri, and Y. Lin: Addit. Manuf., 2016, vol. 10, pp. 58-66.

11. G. Mandil, V.T. Le, H. Paris, and M. Suard: Int. J. Adv. Manuf. Technol., 2016, vol. 85(5), pp. 1835-46.

12. M. Galati and L. Iuliano: Addit. Manuf., 2018, vol. 19, pp. 1-20.

13. T. Scharowsky, V. Juechter, R.F. Singer, and C. Korner: $A d v$. Eng. Mater., 2017, vol. 17(11), pp. 1573-8.

14. X. Wang, X. Gong, and K. Chou: Procedia Manuf., 2015, vol. 1, pp. $278-95$.

15. A. Sidambe: Met. Powder Rep., 2017, vol. 72(3), pp. 200-8.

16. V. Weißmann, P. Drescher, R. Bader, H. Seitz, H. Hansmann, and N. Laufer: Metals., 2017, vol. 7(91), pp. 1-22.

17. Liu, R. Wildman, C. Tuck, I. Ashcroft, and R. Hague: in Solid Freeform Fabrication Symposium, Austin, 2011, pp. 227-238.

18. F. Bahbou and U. Ackelid: in EBAM 2016, Nuremberg, 2016.

19. A. Antonysamya, J. Meyer, and P.B. Prangnellc: Mater. Charact., 2013, vol. 84, pp. 153-68. 
20. D. Herzog, V. Seyda, E. Wycisk, and C. Emmelmann: Acta Mater., 2016, vol. 117, pp. 371-92.

21. X.P. Tan, Y. Kok, Y.J. Tan, M. Descoins, D. Mangelinck, S.B. Tor, K.F. Leong, and C.K. Chua: Acta Mater., 2015, vol. 97, pp. $1-16$.

22. J. Karlsson, A. Snis, H. Engqvist, and J. Lausmaa: J. Mater Process. Technol., 2013, vol. 213, pp. 2019-118.

23. A. Mohammad, A.M. Alahmari, M.K. Mohammed, R.K. Renganayagalu, and K. Moiduddin: Materials., 2017, vol. 10(211), pp. $1-16$.

24. S.S. Rocha, G.L. Abado, G.E. Henriques, and M.A. Nobilo: Braz. Dent. J., 2006, vol. 17(2), pp. 126-9.

25. M. Yan, M.S. Dargusch, T. Ebel, and M. Qian: Acta Mater., 2014, vol. 68, pp. 196-206.

26. ASTM F2924-14 (ASTM International, West Conshohocken, PA, 2014), www.astm.org. Accessed 28 Oct 2021.
27. N. Hrabe and T. Quinn: Mater. Sci. Eng. A., 2013, vol. 573, pp. 264-70.

28. X. Shui, K. Yamanaka, M. Mori, Y. Nagata, K. Kurita, and A. Chiba: Mater. Sci. Eng. A., 2017, vol. 680, pp. 239-48.

29. B. Dutta and F.H. Froes: Met. Powder Rep., 2017, vol. 72(2), pp. 96-106.

30. C. Qiu, G.A. Ravi, and M. Attallah: Mater. Des., 2015, vol. 81, pp. 21-30.

31. P. Wang, P.M. Ling, S. Nai, and S. Lu: Miner. Met. Mater. Soc., 2017, vol. 69(12), pp. 2738-44

32. K. Zhang: PhD Dissertation, University of Brimingham, 2010.

Publisher's Note Springer Nature remains neutral with regard to jurisdictional claims in published maps and institutional affiliations. 